\title{
A CRITICAL DISCOURSE ANALYSIS OF VACCINATION SKEPTICISM IN AMERICAN NEWSPAPERS
}

\section{Prof. Dr. Salih Mahdi Al Mamoori ${ }^{1} \quad$ Hussein Hamid Kareem ${ }^{2}$}

${ }^{1}$ English Department, College of Education for Human Sciences, Babylon, University, Iraq,

Email: salih_mehdi71@yahoo.com

2 University of Babylon. Iraq.

HNSJ, 2022, 3(1); https://doi.org/10.53796/hnsj3125

Published at 01/01/2022

Accepted at 23/12/2021

\begin{abstract}
This research is based on a critical discourse analysis of vaccination skepticism in American newspapers. The aim of this study is to see how verbal and ideological manipulation affects media coverage. Furthermore, this research aims to demonstrate how newspapers cope with skepticism behaviors and how they are reported through the use of numerous language strategies. The study's concern is that American newspapers use language strategies to promote their reports on vaccination skepticism. It is concluded that the number of the strategies used in the reports has a very important role in persuading people to reject vaccinations.

Key Words: CDA, vaccination, skepticism, newspapers, power, Covid.19, and ideology.
\end{abstract}




\section{Introduction}

It is clear that many organizations engage in a variety of skeptical episodes. In reality, the underlying principle behind acts that can be classified as persuasion is to create doubt in people's thoughts while also controlling their brains. As a result, these reports are constantly a source of anxiety for professionals who rely on them for more information. The key goal is to figure out how media reporting are used to reveal existing skepticism. The newspapers are meant to be constructive, but how unbiased they will be is debatable. As a result, certain newspapers, particularly those in the United States, use linguistic words to indicate vaccine skepticism. So, biased terms and policies can be found and such a thing is considered as the problem of the study. It aims to identify how the vaccination skepticism is tackled in the American newspapers.

\section{Critical discourse analysis}

Critical discourse analysis (CDA) as a theory and approach for investigating the relationship between language and power and ideology. Ideology is expressed at all levels of speech in this case, whether in terms of meaning or form. As a result, CDA encompasses a wide range of topics, including genres, context, and discursive practices, as well as societal structures at a higher level. As a result, discourse is a type of social practice (Batstone, 1995).

CDA was created with the goal of deciphering political conversation in mind. The study of how discourse reflects and perpetuates power systems in society is of particular interest to critical discourse analysts (Altschull, 1984).

Discourse is a social practice that entails a dialectical interaction between discursive acts and the settings, institutions, and social structures in which they are enacted. Discourse and social practices have a two-way relationship, according to linguists, because discourses are social practices, and social practices produce and build discourses. Furthermore, experts say that people create discourse purposefully to suit their position and the impression they want to have on the recipients, as well as the relationship between producers and recipients (Bell, 1991).

When CDA is used to highlight the traces of cultural and ideological meaning in spoken and written texts, it can be employed as an objective analytical tool. The CDA provides a broad framework for social research that is focused on solving problems. In linguistics and other disciplines such as anthropology, philosophy, and psychology, the 
term "discourse" is recognized as an umbrella term that includes a broad range of topics. Many research in linguistics suggest that the sentence level cannot be considered the final frontier in language. Discourse is a term that refers to a topic that goes beyond the level of a single statement(Batstone, 1995).

One of CDA's main goals is to use text analysis to discover the roots of dominance and inequality in a society. As a result, van Dijk is concerned with the ways in which discursive methods are used to establish or sustain bias or inequality in a given culture. Van Dijk is primarily interested in mental processes. In terms of analysis, van Dijk gives multiple levels in his method as instruments for illuminating his concepts of "Us" and "Them." (Altschull, 1984).

As a result, Critical Discourse Analysis (CDA) is a technique for identifying missing links, theories, and methodologies that can be used to determine the text's objectives and principles. CDA's development was a foreseen outcome of the CDA Group's efforts(Fairclough, 1989). Fairclough, Van Dijk, Wodak, and others formed the CDA Group in the 1980s to aid CL's transition to CDA. It's critical to demonstrate how CDA differs from DA in that it's transdisciplinary and problem-focused. Because social relations are complicated and require a multi-methodical approach, it focuses on social relations rather than linguistic units analysis(Eagleton, 1994).

\subsection{Power}

The ability to sway others is known as power. It differs from authority in that authority is based on persuasion, whereas power is based on societal influences (Gumperz, 1982). Also, power refers to a scenario in which a person wields authority over others, which might include persuading others to act in ways that are counter to their best interests. The language - power relationship is studied because power is a non-static distinctive aspect of an encounter(Bell, 1991).

However, it is recognized that power is not just a personal issue, but also exists in larger communities. Power manifests itself in a variety of ways, including social, economic, military, and other factors. As a result, power is described as the ability to extort acquiescence or deference from others in order to achieve one's desired goals(Batstone, 1995).

Language is powerful because of those who use it, therefore it cannot be regarded a 
goal in and of itself; rather, it aids in the transformation of power and conformance to virtue or responsibility. Language and power have a definite relationship, which is represented in a variety of ways (Dahl, 1957).

\subsection{Ideology}

One of Karl Marx's followers, Louis Althusser, used the term "ideology" in 1969 to describe how people act in relation to their interests. It's used to influence individuals to act in a certain way, such as when the impoverished go out of their way to help the wealthy(Bell, 1991). The rich-poor divide is unalterable. Ideology, on the other hand, is a set of social functions rather than a set of beliefs (Mills , 1997). Ideology can be found not just in discourse and interaction, but also in semiotics, which encompasses messages, films, and photos, among other things. Ideology can be thought of as a boundary between discursive action and cognition (Altschull, 1984).

Furthermore, ideologies differ from attitudes in that attitudes are held by a certain set of people. When it comes to immigration, for example, people have a wide range of opinions on whether it is good or bad, or whether it should be allowed or rejected (Batstone, 1995).

In fact, the term ideology is still vague at the consciousness level. CDA views ideology as a critical component in dealing with power dynamics, which is why one of the organization's goals is to clarify discourses by deciphering the fundamental speech ideologies in order to illuminate people's actions. As a result, ideology has a broad definition and relates to a diverse range of natural and logical views(Crystal, 2008).

\section{Vaccination}

Vaccination is another method for generating active immunity. Antigens in vaccines stimulate the immune system, resulting in an immunological response that is typically identical to that of a natural infection. Vaccination, on the other hand, protects the receiver from the disease and its potential sequelae. The immunological response to vaccination can be influenced by a variety of circumstances (Silverstein, 2009).

The existence of maternal antibodies, the kind and dose of antigen, the mode of delivery, and the presence of an adjuvant are all factors to consider (e.g., aluminumcontaining material added to improve immunogenicity of the vaccine). The immunological response may be influenced by host factors such as age, nutrition, genetics, and concurrent disease. The more closely a vaccine resembles the disease- 
causing version of the bacterium, the better the vaccination's immune response (Liesegang, 2009).

\section{Skepticism}

It is an attitude toward a specific object with the purpose of making doubts . It is also the belief that true knowledge or knowledge in a specific field is inherently ambiguous. Skeptics are known for their method of suspended judgment, systematic doubt, or criticism (Smith, 2000).

\section{Newspaper}

Newspapers also keep one up to date on what's going on in the community. When one reads newspapers, he or she can learn and know a lot of things, not only about what has happened in the past, but also about what is likely to happen (Stubbs, 1983). As a result, it has been observed that newspapers are easier to learn from than news because they are available everywhere and at any time (Burns, 2002). Newspapers, in fact, provided a wide range of news, including weather forecasts, various reports from other locations, business information, and so on (Elkartea, 2010). Reading a newspaper serves as both a source of knowledge and a source of entertainment. As a result, newspapers could be seen of as more up to date, easily accessible, and a beneficial tool in the research process(Batstone, 1995).

The language of newspapers was substantially influenced by technological advancements in the twentieth century, as they began to compete with newspapers as the only and most acceptable source of information from all over the world. The introduction of radio, television, satellite, and the Internet all helped to modify the language and tradition of news presentation in newspapers. The most latest form of linguistic terms can be found in today's newspaper. Some publications make an effort to develop a refined style for certain purposes(Burns, 2002).

The term 'newspaper' implies that the content of a newspaper is primarily comprised of news and editorial commentary on the news. A newspaper, on the other hand, contains a variety of materials such as images, ads, news analysis, games, and so on. Despite the fact that newspapers cover a wide range of topics, some are specialized to specific topics other than news. Some, for example, are primarily interested in celebrities, television personalities, or even the activities of a certain group or family, such as the royal family(Craig, 2004). 
News is a highly important element of a newspaper because it is the most requested page by readers in every day newspapers. He asserts that news must have values, and that news must be ordered. The value of news is easily influenced by the type of language used by the writer, because the content of the news will vary as a result of the change in language. It is demonstrated that news has particular values, and these values are what define the news's quality. Several things influence this, including prominence, effect, conflict, tome, and so on. These elements are crucial in shaping how readers comprehend and interpret the text or story. They help to shape the ideology that is expressed in the text(Crystal, 2008).

The role of the newspaper is to unearth new information about topics that readers are passionate about. Newspapers also serve a variety of purposes, including expressing ideas, making remarks, stating facts, and more. Introducing noteworthy news, on the other hand, is the criterion by which people assess the news' worth. In most newspapers, subjectivity plays a major role (Craig, 2004).

\section{Methodology}

This section deals with the basic steps that will be followed in order to analyze the data selected.

\subsection{Data collection}

The data is collected from two newspapers. They are Washington Post (https://www.washingtonpost.com/) and New York Times (https://www.nytimes.com/) newspapers. The data collected are two reports taken from each of these two newspapers from 2000 to 2001 online.

\subsection{Model adapted}

The model of this study is Van Dijk's 'Discourse and Manipulation' (2006). This approach is adapted to aid in the analysis of newspaper reports by separating them into two groups: the positive in-group and the negative out-group. Those who protect themselves against vaccination by relying on a certain ideological perspective or conviction constitute the positive in-group. Those who advertise using vaccination represent a negative out-group. Van Dijk employed a number of strategies in his model, and they will be investigated by analyzing the newspaper reports to see how they are applied for a certain ideological point of view. The strategies are represented in the following figure: 
Fig.1 An adapted model of Van Dijk's Strategies (2006 )

(Van Dijk's

Strategies)

Syntactic level

burden, counterfactual, disclaimer, norms expressions, polarization, populism, evidentiality

Rhetorical level

euphemism, hyperbole, irony, metaphor, numbers game
Semantic level actor description, categorization, comparison, consensus, example, generalization, victimization

Pragmatic level authority, implication, national selfglorification, presupposition, vagueness

\subsection{Data analysis}

This section is devoted to the analysis of the data. It is divided into two sections. They are related to the newspapers from which data is collected.

\subsubsection{Washington Post Reports}

Two reports are chosen from this newspaper to be analyzed. They are below:

\section{Report One \\ "Anti-vaccination leaders fuel black mistrust of medical establishment as covid-19 kills people of color" By Peter Jamison, July 17, 2020}

From the beginning of the newspaper report, the reporter uses a number of strategies in order to express the ideology of questioning the validity of vaccines, and one of these strategies is implication "The memory of the horrific Tuskegee syphilis study makes some African Americans suspicious of a coronavirus vaccine", where the writer indicates that the vaccines used against Corona are targeting African people and this thing leads to their killing. The use of such a strategy is the basis for questioning the validity of vaccines to a large degree on the mind of the recipient and convincing him not to use the vaccine.

Another strategy used by the reporter is the strategy of the normal description of the events, where the writer explains that one of the important characters resisted taking 
the vaccine "Beasley, who had previously expressed his resistance toward getting vaccinated", and this person refuses to use the vaccine. Such a thing affects people decision and persuade them to reject using the vaccination.

Another strategy the reporter uses is the consensus strategy, where he makes it clear that Beasley represents all other people who have doubts about the validity of the vaccine "that other players share his doubts". This thing shows the extent to which people do not believe in the effectiveness of the vaccine, and therefore it negatively affects the numbers that can be vaccinated for the purpose of gaining immunity against the Corona epidemic. The lack of vaccination for a group of people certainly leads to the issuance of some doubts about the validity of such vaccines.

The reporter uses another strategy, which is the strategy of irony, where it is put that Beasley will practice his life in general and naturally and without fear of the existence of any epidemic abroad, as he also questions the existence of the epidemic, and thus this thing shows how much people underestimate the epidemic and the extent of their lack of faith in the vaccine. Such behavior leads to an increase in the incidence of the epidemic and its widespread spread.

Another strategy is the burden strategy, where the reporter explains that Beasley does not care about his life and is not likely to have the virus. For this reason, he will go out to enjoy his life normally and advise people who feel afraid of him to stay away or go get the vaccine "If you are scared of me then steer clear, or get vaccinated". Such thoughts lead to sowing doubt in the hearts of others, which will make them stay away from taking vaccinations.

The presupposition strategy is one of the other strategies the reporter uses in the newspaper's report by which he can make it clear that people like Beasley will live their lives normally, and they may die from the epidemic, but they must have their own life. These terms greatly affect the mind of the recipient, especially as they are reports published in well-known and famous newspapers, and thus negatively affect the numbers that will receive the vaccine. 


\section{Report Two \\ "Vaccine opponents outline online campaigns to sow distrust in coronavirus vaccine" \\ By Elizabeth Dwoskin, December 23, 2020}

One of the strategies used in this newspaper report is the consensus strategy, which explains the agreement between a group of people using demonstrations in order to denounce the use of the vaccine "opportunity to sow distrust in vaccination and laid out planned online campaigns to do so, according to a report from an organization opposing misinformation online.

". Where he explains that they have no confidence in this vaccine and therefore they categorically refuse in order to preserve their health. As this group considers the vaccine to be harmful, therefore, it should be avoided and not consent to taking the vaccine.

Another strategy used by the reporter in the strategy of authority, where he explains that there is a group of leaders that will make an agreement between them in order to cast doubts about the existing vaccines "which the leaders, many of whom have huge social media followings, discussed strategies to encourage skepticism and fear of vaccines in the months ahead.". And that these doubts will lead to a natural move away from taking the vaccine. This thing will be done through the media, which is a kind of authority and that people are greatly affected by it.

There is another strategy used by the reporter, which is the example strategy, where the reporter explains that there are some people who suffer from some side effects from the vaccine, and this aspect is used in order to question the validity of the vaccine "people experienced side effects from the vaccine and using those examples to argue dangerous side effects will be widespread". The dissemination of such information negatively affects people greatly as it makes people think about the negative aspects of the vaccine. That's something that makes people throw accusations at the vaccine.

The reporter uses another strategy and the evidentiality strategy, through which he explains that the Facebook authority and administration has banned any ads that lead to promoting against taking the vaccine "We've banned ads that discourage people from 
getting vaccines and reduced the number of people". This shows indirectly and through the implication strategy that there are ads on Facebook that were aimed at urging people to stay away from taking the vaccine. Such advertisements have a great role on the mind of the recipient, as they work to question the validity of vaccines issued from global origins.

In addition, there is the strategy of hyperbole, where the reporter explains that there are a group of people who violate the general rules in order to spread skepticism among the people. The aim of those people is to prevent others from using the vaccine recommended by the World Health Organization "We continue to remove accounts and content that violate our policies and are the only company to work with over 80 fact-checking organizations around the world". Those people believe that the vaccine is dangerous and leads to serious consequences. Therefore, they break the general rules in order to achieve their intended goal.

The reporter uses another strategy, which is the normal description of the events, as he explains that Facebook's policy has banned some public accounts that were plotting against vaccines. Through this strategy, it is revealed that there is a group of people, numbering 100,000, who are carrying out another campaign, which is the campaign to prevent the vaccination "Facebook removed two major groups opposing vaccination, including the 100,000-plus-member Stop Mandatory Vaccination". Using such a number enhances the reader's confidence that there are some doubts about vaccines, which affects the reader's thinking and thus makes him stay away from the vaccine.

\subsubsection{New York Times Reports}

Two reports are also chosen from this newspaper as the data to be abalyzed according the adapted model. They are below:

\section{Report One}

\section{"Antivaccination Activists Are Growing Force at Virus Protests" By Nicholas Bogel-Burroughs, May 2, 2020}

One of the strategies used by the reporter is the strategy of counterfactual to make it clear in this newspaper report that there are riots and demonstrations carried out by people in various cities in order to pressure the authorities to open the complete closure that was the result of the spread of the Corona virus "The protest on Friday in 
Sacramento urging California's governor to reopen the state resembled the rallies that have appeared elsewhere in the country". In fact, this shows that people do not believe, in their ideological perspective, in the existence of a virus, just as they do not believe in the health measures recommended by the World Health Organization, which is social distancing between civilians. This indicates that they do not believe in the validity of the vaccine as well. This is one of the steps to put pressure on city officials to reopen public streets and cities to lead a normal life.

In addition, the reporter uses another strategy, which is the strategy of hyperbole through the use of some terms in some newspaper reports to indicate the extent to which some people are extremist in their own ideas "They were some of the loudest antivaccination activists in the country". Where the reporter explains that those people carry a certain ideology that believe that the virus does not exist and that the vaccine is incorrect, as they believe that this vaccine may harm one way or another human health. The use of the superlative form is evidence that those people carry within them special ideas that push them to avoid the vaccine.

The example strategy is one of the strategies used in this newspaper report in order to convey the idea of rejecting the vaccine. The reporter explains that there are some institutions that reject the vaccine by spreading ideas that may affect the ideology of the individual. One of the ways it affects people is by using protests "The people behind the rally are founders of a group, the Freedom Angels Foundation, which is best known in California for its opposition to state efforts to mandate vaccinations". The reporter explains that the protests are one of the ways in which people express their own ideologies in rejecting the use of the vaccine. Going out in protests is evidence of the division of the group or peoples into two parts. The first division is the in- group, where they are seen as innocent, and these are the people who carry out the protests. The other division is the external group represented by the companies that produce vaccines, which people consider a source of harm and a source of danger.

The presupposition strategy is included within the other strategies used in this report. The reporter explains that those protests have spread in a large number of the United 
States of America, where all people agree to refuse the vaccine. And that this agreement has been made among the people has been widely welcomed. The way of mentioning names of people and places has a great significance and impact on the recipient's mind, as the idea of refusing the vaccine is planted in the recipient's mind definitively "Activists known for their opposition to vaccines have also been involved in protests in New York, Colorado and Texas, where they have found a welcome audience for their arguments for personal freedom and their suspicion of government.". The use of linguistic words has a great impact on human behavior, as it produces a certain ideology and special ideas that oppose or reject the idea of using the vaccine and question it.

\section{Report Two}

\section{“Drug Pitched to Trump for Covid-19 Comes From a Deadly Plant”}

\section{By Heather Murphy, Aug. 20, 2020}

The reporter uses the strategy of the norm description of the events, in which he makes it clear that the source of the treatment or the vaccine is from a poisoned plant "A plant extract trumpeted this week as a "cure" for Covid-19 by the leader of a pillow company is untested and potentially dangerous, scientists say". The use of such strategies in the reports may give an indication of the perspective of the newspaper itself. It may be that the newspaper itself does not encourage the vaccine, and therefore the use of the term "deadly plant" badly affects the truth of the vaccine.

The implication strategy is another strategy used by the reporter in which he implies that the source of the vaccine has not been properly tested "No studies have shown that oleandrin is safe or effective as a coronavirus treatment". And that these linguistic terms used in this report give the opposite meaning. The lack of previous tests may generate fatal results. Such thoughts may be inferred by the reader indirectly and thus force him to stay away from taking the vaccine.

Another strategy used by the reporter in the report is the strategy of evidentiality, where the reporter explains that there is a group of American forces or soldiers who have studied some treatments in order to reach positive results. But through the study, 
there are some plants whose results may be questionable, and among these plants that may be used in treatment is the plant that is used to treat corona "The U.S. Army Medical Research Institute of Infectious Diseases conducted a lab test in May to determine if oleandrin could stop coronavirus infection in cells. The results were "inconclusive,". Such linguistic uses and mentioning some of the names of plants with their reinforcement in some studies may negatively and significantly affect the failure to increase the numbers towards the vaccine.

Another strategy used by the writer is the victimization strategy, where the author explains that most of the plants that are used in treatments are used on animals in the beginning. This is an inhumane behavior and therefore animal welfare associations may oppose the use of such treatments or tests on animals. Where some studies emphasize kindness and non-use of what harms animals, considering that they are creatures that have rights and must be respected and placed in special reserves. And that this bit of testing may affect the health of the vaccine and thus affect the individual's decision to use the vaccine.

The vagueness strategy, together with consensus, is also one of the strategies used, as the reporter points out the absence of some previous studies on these plants and the validity of using this treatment in preventing the increase of cases of corona infection. The absence of previous studies is not a good indicator of the validity of this plant in its use "No known study examining the safety of oleandrin as a treatment for coronavirus or anything else has ever been conducted in such a large group.". As a treatment, publishing such vocabulary in international newspapers has a clear negative impact on the individual's decision, as it leads to questioning the validity of the vaccine, given the absence of previous results or studies on this subject, and therefore the results will be negative in the sense of increased Corona cases and a decrease in the numbers coming to the vaccine. 


\section{Results}

\begin{tabular}{|l|l|l|l|}
\hline $\begin{array}{l}\text { Washington Post } \\
\text { Report One }\end{array}$ & $\begin{array}{l}\text { Washington Post } \\
\text { Report Two }\end{array}$ & $\begin{array}{l}\text { New York } \\
\text { Report one }\end{array}$ & $\begin{array}{l}\text { New York } \\
\text { Report Two }\end{array}$ \\
\hline 1. implication & 1. consensus & 1. counterfactual & $\begin{array}{l}\text { 1. norm } \\
\text { description }\end{array}$ \\
\hline $\begin{array}{l}\text { 2. normal } \\
\text { description }\end{array}$ & 2. authority & 2. hyperbole & 2. implication \\
\hline 3. consensus & 3. example & 3. example & 3. evidentiality \\
\hline 4. irony & 4. evidentiality & 4. presupposition & 4. victimization \\
\hline 5. burden & 5. hyperbole & & 5. vagueness \\
\hline 6. presupposition & $\begin{array}{l}\text { 6. normal } \\
\text { description }\end{array}$ & & \\
\hline & 7. number game & & \\
\hline
\end{tabular}

Fig.2. Analysis results.

From this figure, one can conclude that some newspapers have more influence than others. This depends on the number of the strategies that are used the reports. Such a fact can be seen when examining the difference between the Washington Post and the New York Times newspapers. In can be seen that the Washington Post uses more strategies in its reports. In the first report, there are six strategies used to imply that there are certain doubts about Covid.19. The second report uses seven strategies to give a certain message that people have doubts about the vaccine. In the first report of the New York Times, there are four strategies used. The number is not too many in comparison with those of the Washington Post reports. The second report uses five strategies to imply the skepticism about the vaccine. So, it can be said that the number of the strategies used in each report gives more powerful evidence about vaccine skepticism, which is reflected in newspaper reports as powerful institutions.

\section{Conclusion}

When looking at the analysis of American newspapers, it is clear that these newspapers use exaggeration and language manipulation to describe the topic under consideration. When the Washington Post and the New York Times are mentioned, this is evident. News and news reports for the Washington Post rely on a variety of tactics that are mentioned only in throughout the reports. Knowing these Van Dijk-illustrated strategies might help one choose descriptive words and phrases. The New York Times, for example, use a variety of strategis to focus on a specific ideology, as well as organizations with great persuasion and manipulative power to deliver a particular message. When comparing these two newspapers, one can see that the way the reports 
are released is identical, relying on the same techniques, which, if anything, indicates the depth of US policy in dealing with skepticism issues in different ways. Both newspapers employ the same methods when it comes to the strategies they employ. As though the desired audience is one, most of these methods are reciprocal between the two newspapers. Still, the effect of Washington Post is more powerful that that of the New York Times.

\section{References}

Altschull, J.(1984). Agents of power. New York and London. Longman.

Batstone, R. (1995). Grammar in discourse: Attitude and deniability. In G. Cook and B.

Bell, A. (1991). The Language of news media. London. Blackwell Publishers Ltd.

Burns,L. (2002). Understanding journalism. London. Sage.

Craig, G. (2004). The Media, politics and public life. Australia: Allen and Unwin.

Crystal, D. (2008). A dictionary of linguistics and phonetics. Oxford: Blackwell.

Dahl, R. (1957)."The concept of power". behavioural science. 2.3: 201-2014.

Eagleton, T. (1994). Ideology. London: Longman.

Elkartea, G. (2010). The Press and the media. Spain. Gipuzkoa.

Liesegang, TJ .( 2009). "Varicella zoster virus vaccines: effective, but concerns linger". Canadian Journal of Ophthalmology. 44 (4): 379-84. doi:10.3129/i09126. PMID 19606157.

Fairclough, N. (1989). Language and power. London: Longman.

Gumperz, J. (1982). Discourse strategies. London: Cambridge University Press.

Mills , S.( 1997). Discourse .London: Routledge .

Silverstein, A. (2009). A History of Immunology (2nd ed.). Academic Press. p. 293. ISBN 9780080919461.

Smith, P. (2000). A Concise Encyclopedia of the Bahá'í Faith. Oxford, UK: Oneworld Publications.

Stubbs, M. (1983). Discourse analysis. Oxford: Blackwell.

Van Dijk (2006c). "Discourse and manipulation". In Discourse and Society. Vol.17, No.2: 359-83. London: Sage. https://pdfs.semanticscholar.org. [Accessed in 6 May,2017]. 